\title{
$\mathrm{T} 2$ 위암환자의 침윤깊이에 따른 병리소견 및 예후의 차이 \\ 김세원 · 송선교 · 김상운 \\ 영남대학교 의과대학 외과학교실
}

\section{The Clinical Relevance of Distinguishing pT2 Gastric Cancer According to the Depth of Invasion and a Difference of Prognosis}

\author{
Se Won Kim, Sun Kyo Song, Sang Woon Kim \\ Department of Surgery, \\ College of Medicine, Yeungnam University, Daegu, Korea
}

\section{-Abstract-}

Purpose : A difference of a pathologic characteristic in proportion to depth of invasion analyzed in T2 gastric cancer and a difference of depth of invasion examined an influence to lymph node metastasis and prognosis.

Materials and Methods: The clinicopathologic outcomes of 432 patients who underwent curative resection for pT2 stage gastric cancers from 1995 to 1999 were reviewed retrospectively. We are compared on lymphatic metastasis, stage distribution, histologic classification, Bormann's classification, Lauren classification, vessel invasion, lymphatic invasion, neural invasion and 5-year survival rate of pT2 groups(mp vs. ss).

Results : pT2b(ss) group compare to pT2a $(\mathrm{mp})$ in Lauren classification, ratio of diffused type was higher $(\mathrm{p}<0.05)$ and in Bormann classification, infiltration type was higher $(\mathrm{p}<0.01)$. Vessel and lymphatic invasion, neural invasion showed significant difference between pT2a(mp) and pT2b(ss) $(\mathrm{p}<0.01)$. Difference noted between pT2a $(\mathrm{mp})$ and $\mathrm{pT} 2 \mathrm{~b}(\mathrm{ss})$ group in a lymph node metastatic rate, degree of a metastasis and stage distribution $(\mathrm{p}<0.01)$. On stratifying patients according to depth of invasion, 5-year suvival rate for those with pT2a $(\mathrm{mp})$ group was significantly greater than those with pT2b(ss) group $(82.4 \%$ vs. $47.4 \%$, respectively: $\mathrm{P}<0.01)$. In this study, appeared with the significant prognostic factor in 5-year suvival rate which 
multivariate analysis, depth of invasion $(\mathrm{P}<0.05)$ and lymph node metastasis $(\mathrm{P}<0.01)$ that enforced the total gastric cancer patient who had T2 gastric cancer with the object noted, but for patients with accurately staged $\mathrm{pN} 0$ group, suvival characteristics were similar for pT2a (mp) and pT2b(ss) gastric cancer $(\mathrm{P}=0.97)$.

Conclusion: The subclassification of pT2 gastric cancer into pT2a(mp) and pT2b(ss) is necessary to demonstrate their different prognosis.

Key Words : pT2a(mp), pT2b(ss), N stage, Gastric cancer.

\section{서 론}

위암은 전세계적으로 두 번째로 많은 암 사 망율을 보이고 있고 동아시아, 아프리카, 그리 고 동유럽에서 가장 흔한 암으로 보고되고 있 으며 우리나라에서도 암 관련 사망률 중 2 위를 차지하는 질환으로 ${ }^{1)}$ 치료에 있어 외과적 절제 술과 체계적 림프절 절제술이 생존율 향상에 많은 기여를 하고 있다. ${ }^{2)}$ 위암은 침윤 깊이와 림프절 전이유무가 중요한 예후인자로 알려져 있으며 위암이 고유근층보다 깊이 침범하면 진 행성 위암으로 분류된다. ${ }^{3,4)}$

위암은 위점막에서 발생하는 악성 종양으로 진행되면 장막까지 위의 전층을 침범하게 된 다. TNM 병기 분류에 의하면 점막층 혹은 점 막하층에 국한되면 $\mathrm{T} 1$, 장막 하층 혹은 고유 근층에 침범하면 $\mathrm{T} 2$, 장막층에 침범하면 $\mathrm{T} 3$, 그리고 주위장기를 침범하면 $\mathrm{T} 4$ 로 분류한다. $\mathrm{T} 1$ 과 $\mathrm{T} 3$ 가 수술을 시행하는 가장 흔한 형이 고 $\mathrm{T} 2$ 는 10 38\%정도로 보고되고 있다. ${ }^{5,6)} \mathrm{T} 1$ 은 예후가 좋으며 5년 생존율이 90\%를 넘는 것으로 되어있지만 ${ }^{7}$ T3는 예후가 좋지 않아서 5년 생존율이 30\%정도로 알려져 있다. ${ }^{6)}$

종양학의 일반적인 개념으로는 침윤깊이는 암세포의 증식과 암세포의 더 깊은 조직으로의
성장 그리고 암세포의 증식 시간과 연관이 있 다고 알려져 있다. 게다가 이런 요소들은 혈관, 림프관, 혹은 신경침윤 같은 국소 침윤의 정도 에 영향을 주며 림프절 전이의 기회도 높인다.

$\mathrm{T} 2$ 위암은 예후를 보면 $\mathrm{T} 1$ 조기위암과 $\mathrm{T} 3$ 진행암의 중간 형태로 보여서 예후에 영향을 주는 인자들을 잘 분석하면 적절한 치료 방법 에 도움이 될 것으로 생각된다. 위암의 $\mathrm{TNM}$ 분류에서는 고유 근층 $(\mathrm{mp})$ 침윤위암과 장막 하(ss) 침윤위암이 같은 $\mathrm{T} 2$ 병변으로 분류된 다. 동일한 $\mathrm{T} 2$ 위암이라도 고유 근층 병변에 비해 장막 하 병변은 높은 병기에 분포하는 경 향이 있고, 이는 환자의 예후와도 관련이 있을 것으로 생각된다. 이를 확인 하고자 $\mathrm{T} 2$ 위암에 서 침윤 깊이에 따른 병리적 특성의 차이가 있 는지 분석하고, 침윤깊이의 차이가 환자의 병 기 및 예후에 미치는 영향을 조사하였다. 본 연구는 병리학적 소견과 임상 결과의 측면에서 이 두 병변의 차이를 정의하여 침윤 깊이에 따 라 $\mathrm{T} 2$ 위암을 구별하는 것이 의미 있는가를 확인하고자 시행하였다.

\section{대상 및 방법}

1995년부터 1999년까지 영남의료원 외과에 
서 위암으로 수술을 시행받은 1018 명의 환자 중 에서 $\mathrm{T} 2$ 병변을 가진 432명을 대상으로 하였 다. 환자들은 모두 근치적 수술(R0 resection) 을 받았고 최소 15 개 이상의 임파절 곽청술이 시행되었다. AJCC staging criteria 제 6판에 따라 $\mathrm{T} 2$ 병변을 $\mathrm{T} 2 \mathrm{a}(\mathrm{mp})$ 와 $\mathrm{T} 2 \mathrm{~b}(\mathrm{ss})$ 로 분류하 고 림프절 전이는 $\mathrm{NO}$ (림프절 전이 0개), $\mathrm{N1}$ ( 림프절 전이 1-6개), $\mathrm{N} 2$ (림프절 전이 7-15개), 그리고 $\mathrm{N} 3$ (림프절 전이 16 개 이상)로 분류하 였으며 병기 분류는 IB(T2N0M0), II(T2N1M0), $\mathrm{IIIA}(\mathrm{T} 2 \mathrm{~N} 2 \mathrm{M} 0)$, 그리고 $\mathrm{IV}(\mathrm{T} 2 \mathrm{~N} 3 \mathrm{M} 0)$ 로 하였다. 대상 환자는 병리조직검사 보고서를 토대로 고 유 근층 침윤 $(\mathrm{mp})$ 군과 장막 하 침윤( $\mathrm{ss})$ 군으 로 구분하고, 각 군의 림프절전이 및 병기분포, 조직분화도, 육안적 형태의 분류, Lauren 분류, 혈관 침범, 림프관 침범, 신경 주위 침윤, 그리 고 5년 생존율 등에 대하여 비교 분석하였다. 생존율은 Kaplan-Meier 방법을 이용하여 구하 고 $\log$-rank test로 검정하였다. 예후인자들은 Cox proportional hazards regression model을 사용한 다변량 분석을 통해 분석하였고 $\mathrm{P}$ 값이 0.05 미만일 때 통계적으로 유의한 것으로 판정 하였다. 통계처리는 SPSS for Windows (Version 12.0, SPSS Inc., USA) 프로그램을 이용하였다.

\section{결 과}

\section{1) 각 군의 임상병리학적 특징}

대상 환자 432명 중에서 남자는 303명, 여자 는 129 명으로 성비는 $2.34: 1$ 이었고, 평균연령은 54.7 세였다. 고유 근층 침윤 $(\mathrm{mp})$ 군과 장막 하 침윤(Ss) 군은 각각 141 명과 291 명이었다. 양군 사이의 성별 및 연령별 분포, 조직 분화도는 차이가 없었으나 Lauren 분류에서 장막 하 침

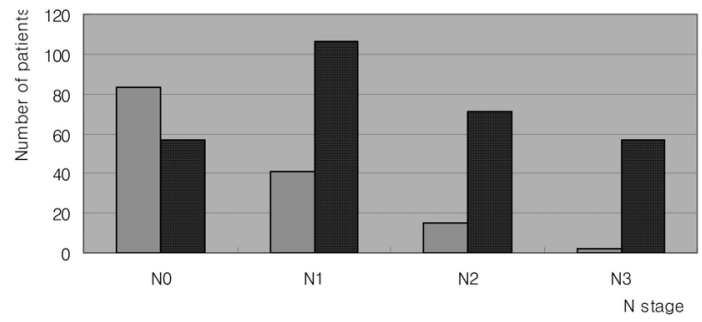

Fig. 1. Patients distribution according to the $\mathrm{N}$ stage in T2 gastric cancer.

윤(ss) 군이 고유 근층 침윤(mp) 군에 비해 미 만형의 비율이 높았고 $(\mathrm{p}<0.05)$, Borrmann 분 류에서도 장막 하 침윤(ss) 군이 고유 근층 침 윤 $(\mathrm{mp})$ 군에 비해 침윤도가 높았다 $(\mathrm{p}<0.01)$. 혈 관 침윤, 림프관 침윤 그리고 신경 주위 침윤 정 도도 양 군 간에 뚜렷한 차이를 보였다 $(\mathrm{p}<0.01)$. 절제된 림프절의 갯수는 양 군 사이에 차이가 없었으나 림프절로의 전이양상 및 병기분포는 고유 근층 침윤 $(\mathrm{mp})$ 군이 141 명 중 $\mathrm{N} 0$ (병기 IB) 83명, N1(병기 II) 41명, N2(병기 IIIA) 15 명, 그리고 N3(병기 IV) 2명으로 총 58명(41.1\%) 이 림프절 전이를 보였고, 장막 하 침윤(ss) 군 에서는 291명중 N0(병기 IB) 57명, N1(병기 II)

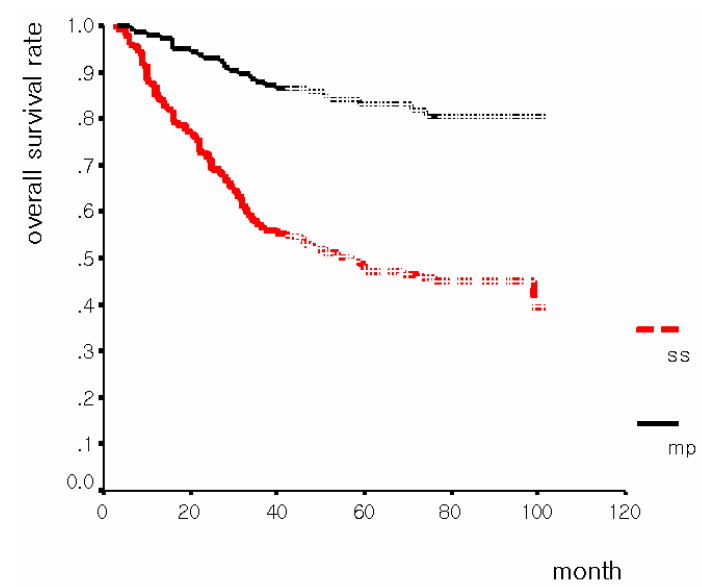

Fig. 2. Survival curves according to the depth of invasion in $\mathrm{T} 2$ gastric cancer $(\mathrm{P}<0.01)$. 
- T2 위암환자의 침윤깊이에 따른 병리소견 및 예후의 차이 -

Table 1. Univariate analysis of clinicopathologic factors in $\mathrm{T} 2 \mathrm{a}(\mathrm{mp})$ and $\mathrm{T} 2 \mathrm{~b}(\mathrm{ss})$ gastric cancer patients

\begin{tabular}{|c|c|c|c|}
\hline Clinicopathologic factors & $\mathrm{T} 2 \mathrm{a}(\mathrm{mp})(\mathrm{n}=141)$ & $\mathrm{T} 2 \mathrm{~b}(\mathrm{ss})(\mathrm{n}=291)$ & $\mathrm{p}$-value \\
\hline Gender & & & NS \\
\hline Male & 101 & 202 & \\
\hline Female & 40 & 89 & \\
\hline Age(median) & $26-76(55.5)$ & $21-78(55.9)$ & NS \\
\hline Differentiation & & & NS \\
\hline well diff. & 28 & 43 & \\
\hline mod. diff. & 36 & 72 & \\
\hline poorly diff. & 64 & 150 & \\
\hline signet ring cell or undiferentiated & 13 & 26 & \\
\hline Lauren classification & & & $\mathrm{p}<0.05$ \\
\hline Intestinal & 63 & 110 & \\
\hline Diffuse/Mixed & 78 & 181 & \\
\hline Borrman classification & & & $\mathrm{p}<0.01$ \\
\hline I & 13 & 16 & \\
\hline II & 30 & 54 & \\
\hline III & 93 & 196 & \\
\hline IV & 5 & 25 & \\
\hline Lymphatic invasion & & & $\mathrm{p}<0.01$ \\
\hline Negative & 95 & 111 & \\
\hline Positive & 46 & 181 & \\
\hline Vessle invasion & & & $\mathrm{p}<0.01$ \\
\hline Negative & 115 & 184 & \\
\hline Positive & 26 & 107 & \\
\hline Neural invasion & & & $\mathrm{p}<0.01$ \\
\hline Negative & 107 & 131 & \\
\hline Positive & 34 & 160 & \\
\hline $\mathrm{N}$ stage & & & $\mathrm{p}<0.01$ \\
\hline NO(stage IB) & 83 & 57 & \\
\hline N1(stage II) & 41 & 106 & \\
\hline N2(stage IIIA) & 15 & 71 & \\
\hline N3(stage IV) & 2 & 57 & \\
\hline Resected lymph node & $39.62 \pm 14$ & $39.35 \pm 15$ & NS \\
\hline Distant metastasis & 2 & 7 & NS \\
\hline
\end{tabular}

106명, N2(병기 IIIA) 71명, 그리고 N3(병기 IV) 2) 각 군의 생존율 비교

57 명으로 총 234 명 $(80.4 \%)$ 이 전이를 보여 전이 고유 근층 침윤 $(\mathrm{mp})$ 군과 장막 하 침윤( $\mathrm{ss})$ 율과 전이의 정도 및 병기분포에서 양 군 간에 군의 5년 생존율 및 생존기간(median survival 유의한 차이를 보였다 $(\mathrm{p}<0.01$, Fig. 1). 원격전이 period)은 각각 $82.27 \%$ 및 89 개월, $47.42 \%$ 및 는 고유 근층 침윤 $(\mathrm{mp})$ 군이 2 명, 장막 하 침 57 개월로서 의미있는 차이를 보였다 $(\mathrm{P}<0.01$, 윤(ss) 군이 7명으로 차이가 없었다(Table 1). Fig. 2). 림프절 전이가 없는 경우에 5년 생존 
- 김세원 · 송선교 · 김상운 -

Table 2. Comparison of 5 year survival rate in T2a(mp) and T2b(ss) gastric cancer patients

\begin{tabular}{|c|c|c|c|}
\hline & $\mathrm{T} 2 \mathrm{a}(\mathrm{mp})(\%)$ & $\mathrm{T} 2 \mathrm{~b}(\mathrm{ss})(\%)$ & p-value \\
\hline $\mathrm{N}(-)$ & 87.95 & 85.96 & NS \\
\hline $\mathrm{N}(+)$ & 74.14 & 38.03 & $\mathrm{p}<0.01$ \\
\hline N1 & 85.37 & 57.55 & $\mathrm{p}<0.01$ \\
\hline $\mathrm{N} 2$ & 53.33 & 29.58 & NS \\
\hline N3 & 0 & 12.28 & NS \\
\hline Total & 82.27 & 47.42 & $\mathrm{p}<0.01$ \\
\hline
\end{tabular}

율은 고유 근층 침윤 $(\mathrm{mp})$ 군이 $87.95 \%$, 장막 하 침윤(ss) 군이 $85.96 \%$ 로 양 군 간에 차이가 없었으나 림프절 전이가 있는 경우에는 고유

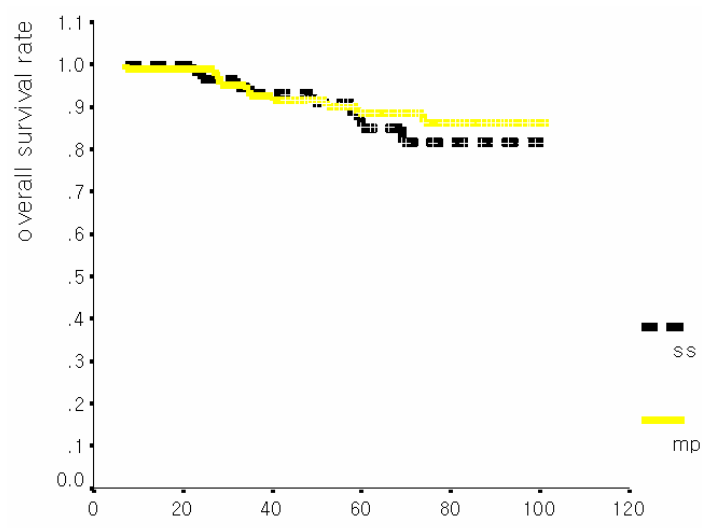

months

Fig. 3. Survival curves of $\mathrm{T} 2$ gastric cancer patients according to the depth of invasion in $\mathrm{LN}(-)$ patients.
근층 침윤 $(\mathrm{mp})$ 군이 $74.14 \%$, 장막 하 침윤( $(\mathrm{ss})$ 군 이 $38.03 \%$ 로 차이를 보였다 $(\mathrm{p}<0.01$, Fig. 3,4). 림프절 전이가 있는 경우에서 $\mathrm{N} 1, \mathrm{~N} 2, \mathrm{~N} 3$ 로

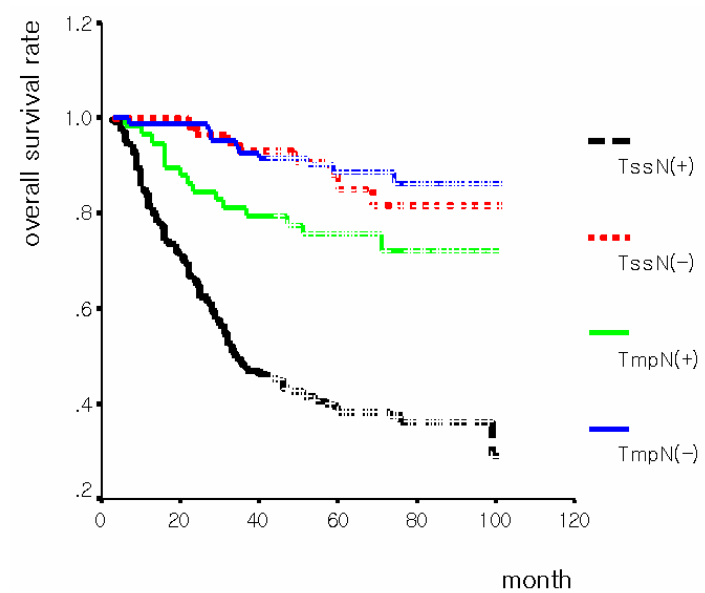

Fig. 4. Survival curves of $\mathrm{T} 2$ gastric cancer patients according to the depth of invasion and nodal metastasis $(\mathrm{P}<0.01)$.

Table 3. Multivariate analysis of prognostic factors in $\mathrm{T} 2 \mathrm{a}(\mathrm{mp})$ and $\mathrm{T} 2 \mathrm{~b}(\mathrm{ss})$ gastric cancer patients

\begin{tabular}{lcccc}
\hline \multirow{2}{*}{ Variable } & \multirow{2}{*}{$\beta^{*} \pm$ S.E. $^{\dagger}$} & R.R. $^{*}$ & \multicolumn{2}{c}{$95 \%$ C.I. $^{\S}$} \\
\cline { 4 - 5 } Depth of invasion & $1.888 \pm 0.236$ & 7.237 & 1.188 & Upper \\
Lymphatic invasion & $1.086 \pm 0.179$ & 0.214 & 0.765 & 1.544 \\
Vessle invasion & $0.837 \pm 0.169$ & 1.103 & 0.600 & 1.167 \\
Neural invasion & $1.226 \pm 0.166$ & 1.512 & 0.886 & 1.698 \\
LN metastasis & $2.695 \pm 0.290$ & 11.098 & 1.504 & 4.829 \\
\hline
\end{tabular}

$* \beta=$ regression coefficiency; $\uparrow$ S.E. = standard error; $\$$ R.R. = ratio of risk (exponential coefficient);

$\S$ C.I. = confidence interval of ratio of risk. 
나누어 비교해보면 $\mathrm{T} 2 \mathrm{aN} 1$ 군과 $\mathrm{T} 2 \mathrm{bN} 1$ 군간 의 5 년 생존율은 $\mathrm{T} 2 \mathrm{aN1}$ 군이 $74.14 \%, \mathrm{~T} 2 \mathrm{bN} 1$ 군이 $57.55 \%$ 로 의미있는 차이를 보였지만 $\mathrm{T} 2 \mathrm{aN} 2$ 군과 $\mathrm{T} 2 \mathrm{bN} 2$ 군, $\mathrm{T} 2 \mathrm{aN} 3$ 군과 $\mathrm{T} 2 \mathrm{bN} 3$ 군간에는 생존율의 차이는 통계적으로 보이지 않았다. (Table 2)

$\mathrm{T} 2$ 병변을 가진 전체 위암환자를 대상으 로 시행한 단변량 분석 결과 Lauren 분류, Borrmann 분류, 혈관 침윤, 림프관 침윤, 신경 주위 침윤, 림프절 전이 그리고 침윤 깊이 등 이 유의하였고 다변량 분석에서 침윤 깊이와 림프절 전이가 유의한 예후인자로 나타났다 (Table 3).

\section{고 찰}

위암이 장막 하층 혹은 고유 근층에까지 침 범하면 $\mathrm{T} 2$ 로 병변을 분류하게 되는데 이는 초 기를 지난 진행성 위암으로 분류된다. 이 $\mathrm{T} 2$ 병변을 2002 AJCC TNM classification 제 6판 에서 $\mathrm{T} 2 \mathrm{a}(\mathrm{mp})$ 와 $\mathrm{T} 2 \mathrm{~b}(\mathrm{ss})$ 로 나누었다. $\mathrm{T} 2 \mathrm{a}(\mathrm{mp})$ 군과 $\mathrm{T} 2 \mathrm{~b}(\mathrm{ss})$ 군의 위암 병변의 병리학적 차 이는 $\mathrm{T} 2 \mathrm{~b}(\mathrm{ss})$ 군이 림프절 전이가 더 많고, 조 직 분화도는 poorly differentiated type이 많고, 그리고 종양의 크기가 더 크다고 보고되고 있 다. ${ }^{9)}$ 본 연구에서도 $\mathrm{T} 2 \mathrm{a}(\mathrm{mp})$ 군의 림프절 전 이는 $41.1 \%$ 이고 $\mathrm{T} 2 \mathrm{~b}(\mathrm{ss})$ 군의 림프절 전이는 $80.4 \%$ 로 의미있게 높게 나왔으며 특히 $\mathrm{T} 2 \mathrm{~b}$ (ss) 군에서 $\mathrm{N} 3$ 가 많은 것으로 조사되었다. 조 직 분화도는 poorly differentiated type이 많았 지만 통계적으로 의미는 없었다.

$\mathrm{T} 2$ 위암환자들의 예후 인자에 대한 몇몇 보 고들에서 림프절 전이(N stage), 혈관 침범, 종 양의 크기, 환자의 나이, 그리고 Lauren 분류
등이 중요한 인자로 보고되고 있다. ${ }^{10-12)}$ 본 연 구에서도 림프절 전이(N stage), Lauren 분류, 육안적 형태의 분류, 혈관 침범, 림프관 침범, 신경 주위 침윤 등이 의미있는 인자들로 분석 되었다. 림프절 전이와 관련된 5년 생존율에서 림프절 전이가 없는 경우에 $\mathrm{T} 2 \mathrm{aN} 0$ 군과 $\mathrm{T} 2 \mathrm{bN} 0$ 군 간의 생존율은 각각 $87.95 \%$ 와 $85.96 \%$ 로 차 이는 없었다. 림프절 전이가 없는 $\mathrm{T} 2$ 위암환자 의 침윤깊이에 따른 비교분석에서는 신경침윤 을 제외한 다른 병리소견은 차이를 보이지 않았 고 침윤깊이는 예후에 영향을 미치지 않는 것으 로 나타났으며 실제 5년 생존율도 양 군 간에 차이를 보이지 않았다. 림프절 전이가 있는 경 우 $\mathrm{T} 2 \mathrm{a}(\mathrm{mp})$ 군 전체의 5 년 생존율은 $\mathrm{T} 2 \mathrm{~b}(\mathrm{ss})$ 군 전체보다 의미있게 높았다. 이는 $\mathrm{T} 2 \mathrm{~b}(\mathrm{ss})$ 군에서 관찰되는 림프절로의 높은 전이율이 병 기상승과 함께 저조한 생존율을 초래하는 것으 로 판단된다. $\mathrm{N}$ stage에 따른 분석에서는 $\mathrm{T} 2 \mathrm{aN1}$ 군의 5 년 생존율이 $\mathrm{T} 2 \mathrm{bN1}$ 군보다 의미있게 높았으며 $\mathrm{N} 2$ 와 $\mathrm{N} 3$ 에서는 두 군 간의 차이가 없었다.

위암의 근치적 수술과 $\mathrm{D} 2$ 림프절 곽청술이 생존율 향상에 영향을 준다고 여러 유럽과 아 시아의 연구 기관에서 보고가 되고 있지만 ${ }^{4,6)}$ 유럽의 두 가지 연구에서는 D2 림프절 곽청술 을 항상 시행하지는 않았고 그 이유는 D2 림 프절 곽청술이 생존율 향상에는 영향을 주지 못하고 수술 후 사망률과 이환율이 높기 때문 이라고 하였다. ${ }^{13,14)}$ 하지만 본 연구에서는 수 술을 시행한 모든 환자에서 D2 림프절 곽청술 이상을 시행하였다. 림프절의 절제 개수도 15 개 이상이 나와야 정확한 $\mathrm{N}$ staging이 가능하다고 하였는데 ${ }^{9)}$ 본원에서 수술한 환자에서 제거된 림프절의 수는 두 군 모두 38 개 이상이었다. 
$\mathrm{TNM}$ 병기 분류에 의하면 T2N0는 stage $\mathrm{IB}, \mathrm{T} 2 \mathrm{~N} 1$ 은 stage II, T2N2는 stage IIIA로 분 류가 된다. 본 연구에서 $\mathrm{T} 2 \mathrm{aNO}(\mathrm{IB})$ 는 5 년 생 존율이 $87.9 \%$ 로 가장 좋은 생존율을 보였다. 그런데 $\mathrm{T} 2 \mathrm{bN} 0(\mathrm{IB})$ 와 $\mathrm{T} 2 \mathrm{aN} 1(\mathrm{II})$ 은 5 년 생존율 이 $85.96 \%$ 와 $85.37 \%$ 로 통계학적으로 차이가 없었고, $\mathrm{T} 2 \mathrm{bN} 1$ (II)과 $\mathrm{T} 2 \mathrm{aN} 2$ (IIIA)도 5년 생존 율이 $57.55 \%$ 와 $53.33 \%$ 로 역시 통계학적으로 차이가 없었다. 그러므로 현재의 TNM staging 이 $\mathrm{T} 2$ 위암 환자들에서는 예후를 적절히 반영 하지 못한다고 할 수도 있을 것이고 $\mathrm{T} 2 \mathrm{a}$ 군과 $\mathrm{T} 2 \mathrm{~b}$ 군의 예후가 다르다고 할 수도 있어서 여 기에 관한 더 많은 연구가 진행되어서 $\mathrm{T} 2$ 위 암 환자들의 적절한 staging이 고려되어야 할 것으로 생각된다.

\section{요 약}

림프절 전이를 동반하지 않은 $\mathrm{T} 2$ 위암에서 장막 하 침윤(ss) 군은 고유 근층 침윤 $(\mathrm{mp})$ 군 과 비교해서 예후 및 병리소견의 차이가 없었 다. 하지만 $\mathrm{T} 2$ 위암에서 장막 하 침윤( $\mathrm{ss}$ ) 군 은 고유 근층 침윤 $(\mathrm{mp})$ 군에 비해 진행된 병 리소견을 보이는 빈도가 높으며 림프절 전이도 높은 것으로 나타났고 다변량 분석에서는 침윤 깊이와 림프절 전이가 유의한 예후인자로 나타 났다. 장막 하 침윤(Ss) 군에서 관찰되는 림프 절로의 높은 전이율이 병기상승과 함께 저조한 생존율을 초래하는 것으로 판단된다. 그러므로 림프절 전이를 동반한 장막 하 침윤( $\mathrm{SS}$ ) 군의 환자에 대해서는 적극적인 보조요법과 경과관 찰이 검토되어야 할 것이다. 아울러 현재의 TNM staging이 T2 위암 환자들에서는 예후 를 적절히 반영하지 못한다고 생각되므로 $\mathrm{T} 2$
를 $\mathrm{T} 2 \mathrm{a}$ 와 $\mathrm{T} 2 \mathrm{~b}$ 로 나누어 여기에 관한 더 많은 연구가 진행되어서 $\mathrm{T} 2$ 위암 환자들의 적절한 staging을 고려하여야 할 것으로 생각한다.

\section{참 고 문 헌}

1. Korea national statistical office. Annual report of the cause of death statistics. 2004.

2. Maruyama K, Sasako M, Kinoshita T, Sano T, Katai H, Hada M. Should systematic lymph node dissection be recommended for gastric cancer? Eur J Cancer 1998 Sep;34(10): 1480-9.

3. Kim JP, Lee JH, Kim SJ, Yu HJ, Yang HK. Clinicopathologic characteristic and prognostic factors in 10783 patients with gastric cancer. Gastric Cancer 1998;1:125-33.

4. Siewert JR, Bottcher K, Stein HJ, Roder JD. Relevent prognostic factors in gastric cancer: ten-year results of the German Gastric Cancer Study. Ann Surg 1998 Oct;228(4):449-61.

5. Maehara Y, Anai H, Moriguchi S, Watanabe A, Tsujitani S, Sugimachi K. Gastric carcinoma invading muscularis propria and macroscopic appearance. Eur J Surg Oncol 1992 Apr;18(2): 131-4.

6. Jatzko GR, Lisborg PH, Denk H, Klimpfinger M, Stettner HM. A 10-year experience with Japanese type radical lymph node dissection for gastric cancer outside of Japan. Cancer 1995 Oct 15;76(8):1302-12.

7. Folli S, Morgagni P, Roviello F, De Manzoni G, Marrelli D, Saragoni L, et al. Risk factors for lymph node metastases and their prognostic significance in early gastric cancer (EGC) for the Italian Research Group for Gastric Cancer (IRGGC). Jpn J Clin Oncol 2001 Oct;31(10): 495-9.

8. Greene FL, Page DL, Fleming ID, Fritz AG, 
Balch CM, Haller DG, et al. AJCC cancer staging manual. 6th edition. New York:Springer;2002.

9. Sarela AI, Turnbull AD, Coit DG, Klimstra D, Brennan MF, Karpeh MS. Accurate lymph node staging is of greater prognostic importance than subclassification of the T2 category for gastric adenocarcinoma. Ann Surg Oncol 2003 Aug;10(7):783-91.

10. Yokota T, Kunii Y, Teshima S, Yamada Y, Saito T, Kikuchi S, et al. Gastric cancer with invasion limited to the muscularis propria. Int Surg 1999 Jan-Mar;84(1):7-12.

11. Isozaki H, Fujii K, Nomura E, Mabuchi H, Nishiguchi K, Hara $\mathrm{H}$, et al. Prognostic factor of advanced gastric carcinoma without serosal invasion (pT2 gastric carcinoma). Hepatogas- troenterology 1999 Jul-Aug;46(28):2669-72.

12. Okuno K, Shigeoka H, Tanaka A, Hirai N, Matsumura E, Yasutomi M. Clinicopathological evaluation of T2-gastric cancer among age groups. Hepatogastroenterology 2000 Jul-Aug; 47(34):1180-2.

13. Bonekamp JJ, Hermans J, Sasako M, Van De Velde CJH. Extended lymph-node dissection for gastric cancer. N Engl J Med 1999 Mar 25;340(12):908-14.

14. Cuschieri A, Weeden S, Fielding J, Bancewicz J, Craven J, Joypaul V, et al. Patient survival after D1 and D2 resections for gastric cancer: long-term result of the MRC randomized surgical trial. Surgical Cooperative Group. $\mathrm{Br}$ J Cancer. 1999 Mar;79(9-10):1522-30. 